\title{
Abnormalities in connectivity of white-matter tracts in patients with familial and non-familial schizophrenia
}

\author{
Q. Wang ${ }^{1}$, W. Deng ${ }^{1}$, C. Huang ${ }^{1}$, M. Li ${ }^{1}$, X. Ma ${ }^{1}$, Y. Wang ${ }^{1}$, L. Jiang ${ }^{1}$, S. Lui ${ }^{2}$, X. Huang ${ }^{2}$, S. E. Chua ${ }^{3}$, \\ C. Cheung ${ }^{3}$, G. M. McAlonan ${ }^{3}$, P. C. Sham ${ }^{3}$, R. M. Murray ${ }^{4}$, D. A. Collier ${ }^{5}$, Q. Gong ${ }^{2 *}$ and T. Li ${ }^{1,4,5 *}$ \\ ${ }^{1}$ The Psychiatric Laboratory and Department of Psychiatry, State Key Laboratory of Biotherapy, West China Hospital, Sichuan University, \\ Chengdu, China \\ ${ }^{2}$ Huaxi MR Research Centre, Department of Radiology, West China Hospital, Sichuan University, Chengdu, China \\ ${ }^{3}$ Department of Psychiatry, The University of Hong Kong, Pokfulam, S.A.R. China \\ ${ }^{4}$ Department of Psychological Medicine and Psychiatry, Institute of Psychiatry, King's College London, UK \\ ${ }^{5}$ MRC SGDP Centre, Institute of Psychiatry, King's College London, UK
}

Background. Abnormalities in the connectivity of white-matter (WM) tracts in schizophrenia are supported by evidence from post-mortem investigations, functional and structural magnetic resonance imaging (MRI) and diffusion tensor imaging (DTI). The aims of this study were to explore the microstructural changes in first-episode schizophrenia in a Han Chinese population and to investigate whether a family history of psychiatric disorder is related to the severity of WM tract integrity abnormalities in these patients.

Method. T1-weighted MR and DT images were collected in 68 patients with first-episode schizophrenia [22 with a positive family history (PFH) and 46 with a negative family history (NFH)] and 100 healthy controls. Voxel-based analysis was performed and WM integrity was quantified by fractional anisotropy (FA). Cluster- and voxel-level analyses were performed by using two-sample $t$ tests between patients and controls and/or using a full factorial model with one factor and three levels among the three sample groups (patients with PFH or NFH, and controls), as appropriate.

Results. FA deficits were observed in the patient group, especially in the left temporal lobe and right corpus callosum. This effect was more severe in the non-familial schizophrenia than in the familial schizophrenia subgroup.

Conclusions. Overall, these findings support the hypothesis that loss of WM integrity may be an important pathophysiological feature of schizophrenia, with particular implications for brain dysmaturation in non-familial and familial schizophrenia.

Received 1 May 2010; Revised 25 October 2010; Accepted 15 November 2010; First published online 16 December 2010

Key words: DTI, family history, first episode, fractional anisotropy, schizophrenia, voxel-based analysis.

\section{Introduction}

Schizophrenia is a complex brain disorder with putative disconnectivity between multiple brain regions (Friston \& Frith, 1995). Several lines of evidence have supported the presence of abnormal white-matter (WM) tract integrity in patients with schizophrenia. Post-mortem investigations have shown neuronal deficits related to glial elements, which may lead to abnormalities in myelination and synaptic integrity (Hof et al. 2003; Harrison \& Weinberger, 2005).

* Address for correspondence: Professors Tao Li or Qiyong Gong, 28 Dian Xin Nan Road, West China Hospital, Chengdu, Sichuan, 610041, P.R. China.

(Email: xuntao26@hotmail.com)
Structural brain imaging research pertaining to diffusion tensor imaging (DTI) studies has also suggested that deficits in WM tracts exist in patients with schizophrenia (Kubicki et al. 2002a, 2005, 2007; Kanaan et al. 2005; Karlsgodt et al. 2008; Lee et al. 2009; Phillips et al. 2009). Furthermore, functional brain imaging studies have suggested that patients with schizophrenia may show impaired fronto-temporal functional connectivity (Friston, 1998; Lawrie et al. 2002; Liu et al. 2008; Kim et al. 2009). Although these are promising findings, the evidence supporting abnormal WM tract integrity in patients with schizophrenia remains equivocal (Assaf \& Pasternak, 2008). There are several possible reasons for this. First, studies used different standards for data acquisition and data analysis and different methods for data 
post-processing. Second, small sample size is a limitation in most of the studies. Third, some confounding factors, such as patient age, course of illness and medication use, may not have been controlled adequately. Therefore, definitive pathophysiological evidence of abnormal WM tract integrity in schizophrenia has yet to be confirmed.

DTI is a useful tool for assessing WM structural integrity and connectivity in vivo because it yields a series of quantitative measures such as fractional anisotropy (FA), which reflects the integrity of WM tracts. FA reduction has been found in many parts of the principal WM bundles in schizophrenia, with diverse results across studies (Kubicki et al. 2002b, 2003; Ardekani et al. 2003; Sun et al. 2003; Wang et al. 2004). Genetic factors also play a substantial role in the pathogenesis of schizophrenia. Some of the brain morphological deficits seen in schizophrenia are thought to be related to genetic risk (Bartley et al. 1997; Callicott \& Weinberger, 1999; Rijsdijk et al. 2005), and the heritability of total brain volume has been estimated to be up to $94 \%$ (Bartley et al. 1997; Rijsdijk et al. 2005). Twin studies in schizophrenia have reported that the change in grey matter may be heritable (Baare et al. 2001; Koolschijn et al. 2008). Previous investigations have suggested that the non-psychotic relatives of patients with schizophrenia have brain volume deficits that are similar to those seen in the patients themselves, albeit less severe (Gogtay et al. 2003; Job et al. 2003, 2005, 2006; McDonald et al. 2006; Ho, 2007). Studies of twins discordant for schizophrenia have found liability-related decreases of grey matter volume (Baare et al. 2001; Cannon et al. 2002; Hulshoff Pol et al. 2004, 2006b) and increases of WM volume (Hulshoff Pol et al. 2006a,b).

However, the role of family history is still uncertain. For example, in a study using a large sample size, Honea et al. (2008) found that brain regional differences may be a weak intermediate phenotype for schizophrenia. Wood et al. (2005) found that a family history of schizophrenia was not associated with a greater degree of structural brain abnormalities in an ultra-highrisk group. DeLisi et al. (1988) found that conventional volumetric quantification of ventricular space failed to reveal differences between high-risk participants and controls; however, by using apparent diffusion coefficients (ADCs) to assess the ventricular space change, they found a significant difference between the participants at high risk and the controls.

In the present study, we aimed to explore the microstructural changes in first-episode schizophrenia in a Han Chinese population, and to investigate whether a family history of psychiatric disorders is related to the severity of WM tract integrity abnormalities in such patients.

\section{Method}

\section{Participants}

We recruited 68 participants with schizophrenia from in-patient and out-patient psychiatric units in West China Hospital, Sichuan University. The patients were assessed by one of two qualified psychiatrists (W.D. and M.L.) shortly after presentation in their first episode of psychotic illness to the mental health services. The psychiatric history of each patient was reviewed to exclude those with a previous history of any major psychiatric disorder, including psychotic, affective and schizo-affective disorders, head trauma, drug abuse and neurological disorders. Diagnosis was made according to DSM-IV criteria. All participants were interviewed using the Structured Clinical Interview for the DSM-IV (SCID-P for patients and SCID-NP for controls). All patients were followed up for at least 6 months to confirm the diagnosis, especially those participants who were initially diagnosed as schizophreniform psychosis. Thirty out of 68 patients were neuroleptic-naive at the time of magnetic resonance imaging (MRI) scanning, and the remaining 38 [23 with a negative family history $(\mathrm{NFH})$ and 15 with a positive family history $(\mathrm{PFH})$ of schizophrenia] had been minimally treated with antipsychotics such as risperidone or olanzapine at low dosage (ranging from 25 to $75 \mathrm{mg}$ of chlorpromazine daily dose equivalents) for a brief duration of less than 3 days prior to MRI scanning.

Patients also underwent further clinical evaluation, which included symptoms on the Positive and Negative Syndrome Scale (PANSS; Kay et al. 1987) and global functioning on the Global Assessment of Functioning (GAF; Hall, 1995). Healthy controls $(n=100)$ were recruited from the same districts as the cases; these individuals were excluded if their first-degree relatives suffered from any mental illness. The age of the patients and controls at examination was less than 45 years, and all participants were righthanded.

Family psychiatric history was obtained by interviewing the patients and both parents, and also other first-degree relatives (e.g. sibling and offspring) where possible, who provided information on family history in details during the clinical interview. This study adopted the definition of family history as described by $\mathrm{Xu}$ et al. (2008). Patients with PFH were defined as having at least one relative with schizophrenia in their first- or second-degree relatives; otherwise, they were defined as patients with NFH. Of the 68 patients studied, 22 were found to have PFH. Within the PFH group, four had first-degree relatives (two mothers, one father and one sister) and the other 18 had seconddegree relatives with a history of schizophrenia. 
All participants were Han Chinese and provided written informed consent. This study was approved by the Institutional Review Broad of West China Hospital, Sichuan University.

\section{MRI scans}

All participants underwent MRI scanning in the Department of Radiology at West China Hospital using a Signa 3.0 T scanner (GE Medical Systems, USA) with an eight-channel phase array head coil. In our MRI unit, our usual practice to ensure quality assurance of MRI images is based on an in-house protocol based on Jia et al. (2010), in which we use phantoms to measure signal-to-noise ratio (SNR) and image uniformity on a daily basis, noting the voltage of the transmit radiofrequency amplifier, etc. (Firbank et al. 2000). High-resolution DTI data were acquired by using a single-shot spin echo planar imaging (EPI) sequence [repetition time/echo time $(\mathrm{TR} / \mathrm{TE})=10000 /$ $70.8 \mathrm{~ms}, 3-\mathrm{mm}$ axial slices with no gap, matrix = $256 \times 256(0.94 \mathrm{~mm} \times 0.94 \mathrm{~mm} \times 3 \mathrm{~mm})$, field of view $(\mathrm{FOV})=24 \mathrm{~cm}^{2}$, acquisition time $\left.=5 \mathrm{~min} 40 \mathrm{~s}\right]$. The DTI sequence used in this protocol included 15 diffusion gradient directions $\left[b=1000 \mathrm{~s} / \mathrm{mm}^{2}\right.$, number of excitations $(\mathrm{NEX})=2$ ] and one volume without diffusion weighting $(b=0, \mathrm{NEX}=2)$ for 42 slices throughout the whole brain. Anatomical three-dimensional spoiled gradient (3D-SPGR) T1 data were also acquired for registration purposes $[\mathrm{TR} / \mathrm{TE}=8.5 / 3.4 \mathrm{~ms}, 1-\mathrm{mm}$ axial slices, matrix $=512 \times 512, \mathrm{FOV}=24 \mathrm{~cm}^{2}$, inversion time $(\mathrm{TI})=400 \mathrm{~ms}, \mathrm{NEX}=1$ ]. All scans were reviewed by an experienced neuroradiologist to exclude obvious gross abnormalities.

\section{Image processing}

Images were processed and analysed with SPM5 software (www.fil.ion.ucl.ac.uk/spm/software/spm5/). FA maps were generated from each participant's DTI scan using the freely available DTIstudio software (http://cmrm.med.jhmi.edu/). Prior to FA calculation, the DTI scans were realigned using the built-in function in DTIstudio so that each DTI image $(b=0 \mathrm{~s}$ / $\mathrm{mm}^{2}$ ) was corrected for motion. Two patients with schizophrenia and one normal control were excluded in this study because of head and body motion. All 3D-SPGR images were corrected for inhomogeneity, normalized, and segmented using an integrated generative model (unified segmentation; Ashburner \& Friston, 2005) with default parameters. The DTI dataset was registered with the anatomical T1 by mutualinformation co-registration between the $b=0$ image and the T1 image. The normalization parameter of the T1 image was used to normalize the FA map to standard space. The normalized FA maps were resliced to $2 \mathrm{~mm} \times 2 \mathrm{~mm} \times 2 \mathrm{~mm}$ and smoothed with a 6-mm full-width at half-maximum (FWHM) isotropic Gaussian kernel (Kubicki et al. 2005; Winterer et al. 2008). An explicit mask for statistical analysis was created by averaging the WM mask of all subjects and threshold at 0.2 (SPM Masking Toolbox; Ridgway et al. 2009).

\section{Statistical analyses}

Pearson's $\chi^{2}$ test, Student's $t$ test and analysis of variance (ANOVA) were used to compare the distribution and differences of categorical and continuous data respectively. Cluster- and voxel-level analyses were performed by using a full factorial model of twosample $t$ tests between the patients and controls and/or a full factorial model of one factor and three levels statistical comparisons among the three sample groups (PFH, NFH and control), as appropriate. Age, gender and educational attendance were included as covariates. Cluster-level significance probability was set at $p<0.05$ (uncorrected) with cluster voxels $>50$ in two-sample $t$ tests (Cheung et al. 2010). In this exploratory analysis, voxel-level significance probability was set at $p<0.001$ (uncorrected) with cluster voxels $>50$ (Ke et al. 2009) in a full factorial model of one factor and three levels statistical comparisons among the three sample groups. For comparison among the three groups, the results in the group mapping analysis were saved to files and imported into the MarsBar toolbox and the mean values of FA of each region were extracted to be calculated for each subject (Cheung et al. 2008; Jia et al. 2010). These values were further analysed using the Statistical Package for Social Sciences (SPSS) for Windows version 13.0 (SPSS Inc., USA). Bonferroni correction was applied for multiple comparisons and the level of statistical significance was set at $p<0.05$ [12 comparisons (three groups $\times$ four voxels) were set].

\section{Results}

\section{Demographic characteristics}

The demographic characteristics of the participants are shown in Table 1. There were no significant differences in mean age $(t=-1.14, p=0.256$, range $=$ $15-45$ years), gender distribution (Pearson's $\chi^{2}=0.395$, $p<0.53)$ or mean educational attendance $(t=-1.578$, $p=0.116$ ) between the patients and controls. Significant differences in educational attainment were found among the patients in the $\mathrm{PFH}, \mathrm{NFH}$ and control groups $(F=4.30, p<0$. 015); however, no significant differences were observed for the mean age $(F=0.650$, 
Table 1. Demographic profile of participants [values are mean (s.D.)]

\begin{tabular}{|c|c|c|c|c|}
\hline & \multirow[b]{2}{*}{ Controls } & \multicolumn{3}{|l|}{ Cases } \\
\hline & & Total & $\begin{array}{l}\text { PFH group } \\
\text { (drug) }\end{array}$ & $\begin{array}{l}\text { NFH group } \\
\text { (drug) }\end{array}$ \\
\hline$n$ & 100 & 68 & $22 / 15$ & $46 / 23$ \\
\hline Age (years) & $25.58(8.07)$ & $24.13(7.96)$ & $24.00(8.91)$ & $24.20(7.74)$ \\
\hline Educational attainment (years) & $12.8(3.35)$ & $11.99(3.18)$ & $10.59(3.61)$ & $12.65(2.75)$ \\
\hline Age range (years) & $15-45$ & $16-45$ & $16-45$ & $15-44$ \\
\hline Gender $(\mathrm{M} / \mathrm{F})$ & $52 / 48$ & $32 / 36$ & $7 / 15$ & $25 / 21$ \\
\hline Age at onset (years) & & & $23.15(8.12)$ & $23.42(7.86)$ \\
\hline Duration of illness (months) & & & $9.15(16.46)$ & $8.73(14.58)$ \\
\hline PANSS-P & & & $26.83(6.03)$ & $25.79(6.58)$ \\
\hline PANSS-N & & & $19.70(8.30)$ & $19.53(8.21)$ \\
\hline PANSS-G & & & $49.91(9.65)$ & $50.06(10.85)$ \\
\hline PANSS-T & & & $96.43(14.36)$ & $95.38(19.98)$ \\
\hline GAF & & & $27.87(7.02)$ & $26.81(10.55)$ \\
\hline
\end{tabular}

PFH, Positive family history; NFH, negative family history; M, male; F, female; PANSS, Positive and Negative Syndrome Scale; PANSS-P, subscales for positive symptoms; PANSS-N, subscales for negative symptoms; PANSS-G, subscales for general psychopathological symptoms; PANSS-T, total score of PANSS; GAF, Global Assessment of Functioning.

For cases and controls, there were no differences in age $[t(166)=-1.14, p<0.256]$, educational attendance $[t(166)=-1.578$, $p<0.123]$ or gender $\left[\chi^{2}(1, \mathrm{df}=167)=0.395, p<0.530\right]$. For control, PFH and NFH groups, there were no differences in age $[F(2)=0.650, p<0.523]$ but there was a difference in educational attendance $[F(2)=4.303, p<0.015]$. Post-hoc educational attendance differed between the control and PFH groups $(p<0.004)$, and between PFH and NFH groups $(p<0.015)$, but not between the control and NFH groups $(p<0.798)$. Gender did not differ among the groups $\left[\chi^{2}(3, \mathrm{df}=166)=1.37, p<0.50\right]$.

$p<0.52$ ) and gender ratio (Pearson's $\chi^{2}=3.42, p<0.18$ ) among these groups. In the subgroup comparisons, differences in educational attainment were found between the control and PFH groups, and between the $\mathrm{PFH}$ and NFH groups. Both control and NFH groups had significantly higher educational attainment than the PFH group (Table 1).

\section{Comparison between the patients and controls}

Figure 1 and Table 2 show that, compared with the controls, FA in the patients was lower in the right cerebral sublobar extranuclear WM of the corpus callosum (RCC), left cerebral sublobar extranuclear WM of the corpus callosum (LCC) and left temporal lobe WM (LT) when stringent cluster-level analysis was adopted. The voxel- and cluster-level maps were very similar in the regions showing lower FA in the patients, although the voxel-level maps also showed additional regions with increased FA in the patients, but generally with very small spatial extent $(<50)$. This difference did not exist in the cluster-level maps.

\section{Comparison between the PFH, NFH and control groups}

Figure 2 and Table 3 show that, by using analysis of covariance (ANCOVA) in SPM5, we found significant differences in the FA values among the three groups in the RCC, LT, right cerebral parietal lobe precuneus (RPP), and left cerebral occipital lobe precuneus (LOP). The mean FA values from all participants were then extracted in these four regions and compared among the PFH, NFP and control groups by ANCOVA with SPSS. Significant differences in these regions were confirmed after a Bonferroni multiple correction test (12 comparisons). In the between-group comparison, the mean FA values in both the PFH and $\mathrm{NFH}$ groups were lower in all four regions when compared with the control group, and the NFH group had lower FA values in the four regions when compared with the PFH group. In addition, there were no significant associations between the duration of illness or the GAF score, on the one hand, and FA values of the four regions, on the other, in patients with schizophrenia $(p>0.05)$. We also did not find any significant difference in FA values in the four brain regions between the patients who were neuroleptic-naive and those who were on medication $(p>0.05)$.

\section{Discussion}

In line with previous studies, this study supports the finding that patients with first-episode schizophrenia show callosal (Price et al. 2005) and temporal WM abnormalities (Lim et al. 1999; Wang et al. 2003, 2004) in the form of FA deficits compared with controls. 


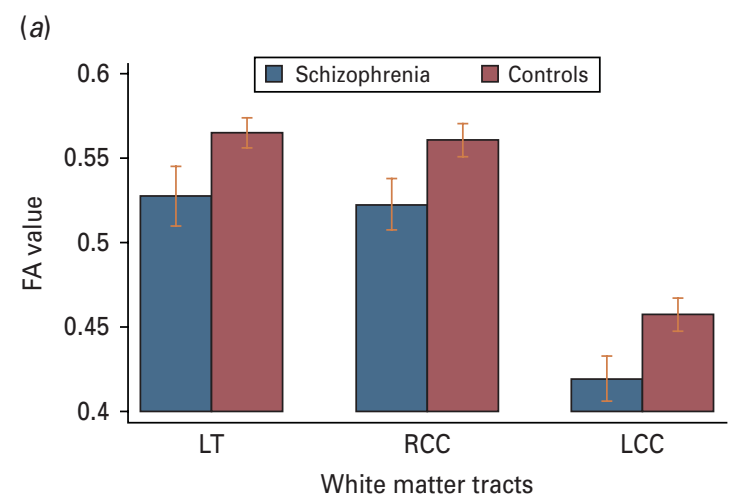

(b)

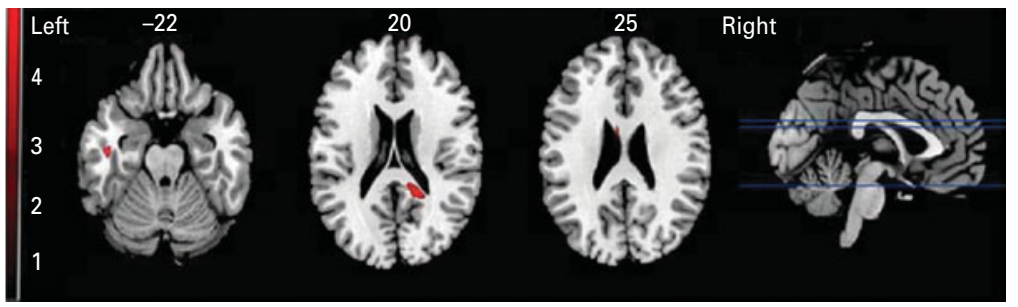

Fig. 1. Comparison between cases and controls: in the right cerebral sublobar extranuclear white matter (WM) of the corpus callosum (RCC), left cerebral temporal lobe subgyral WM (LT) and left cerebral sublobar extranuclear WM of the corpus callosum (LCC) regions, different fractional anisotropy (FA) values were obtained between the patients and normal controls at the uncorrected cluster level $(p<0.05)$.

Table 2. Comparison between cases with schizophrenia and controls

\begin{tabular}{lcl}
\hline Region (MNI coordinates) & $K$ & $\begin{array}{l}p \text { (cluster } \\
\text { level) }\end{array}$ \\
\hline LT $(-45,-16,-22)$ & 395 & 0.0216 \\
RCC $(18,-45,20)$ & 916 & 0.0012 \\
LCC $(-6,-14,25)$ & 308 & 0.0388 \\
\hline
\end{tabular}

LT, Left cerebral temporal lobe subgyral white matter (WM) ; RCC, right cerebral sublobar extranuclear WM of corpus callosum; LCC, left cerebral sublobar extranuclear WM of corpus callosum; $K$, number of voxels ; MNI, Montreal Neurological Institute.

Moreover, the three-group ANOVA revealed that the most striking FA deficits in the PFH and NFH patients were located in the right cerebral sublobar extranuclear WM, that is the posterior portion of the corpus callosum (RCC), as compared with controls. Taken together with the RPP, LT and LOP FA deficits, our findings indicate the presence of widespread temporoparieto-occipital WM disconnectivity in the disorder.

Temporal and callosal WM abnormalities have been widely reported in schizophrenia (Lim et al. 1999; Shenton et al. 2001; Steel et al. 2001; Minami et al. 2003; Wang et al. 2003, 2004; Kanaan et al. 2005; Lee et al.
2009; Phillips et al. 2009). Our results are also partly in line with the findings of Schulze et al. (2003) and Wood et al. (2005); the latter speculated that the mechanisms resulting in gross morphological anomalies in the hippocampus and anterior cingulate cortex in psychosis were mainly due to environmental factors rather than genetic loading. Cumulative evidence from FA studies supports the involvement of the corpus callosum in the pathology of inter-hemispheric connectivity (Price et al. 2005; Cheung et al. 2008; Rotarska-Jagiela et al. 2008; Gasparotti et al. 2009) as the principal WM tract in the brain with homotypic connections to the contralateral cortex (Bloom \& Hynd, 2005; Gasparotti et al. 2009). In addition, several studies have reported grey matter reductions of the lateral and medial temporal cortices in schizophrenia (Narr et al. 2004; Goldman et al. 2008; Honea et al. 2008). The temporal grey matter deficits were presumed to be related to auditory sensory (Rabinowicz et al. 2000) and neurocognitive impairment in patients with schizophrenia (DeLisi, 2001; Harrison, 2004; Green et al. 2005; Yamada et al. 2007). This study is in line with previous findings that indicated that temporal neocortical networks deficits may be related to schizophrenia (Phillips et al. 2009). Our finding of reduced FA in WM adjacent to the right precuneus concurs with that reported in the first DTI study of subjects with first-episode schizophrenia (Cheung 


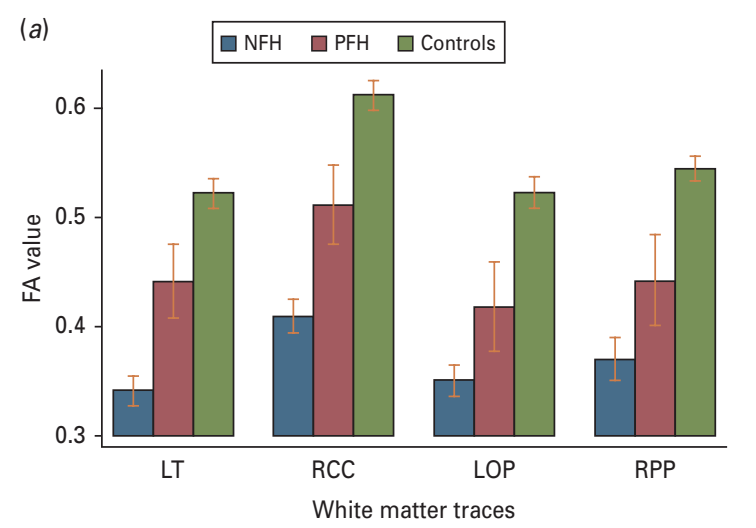

(b)

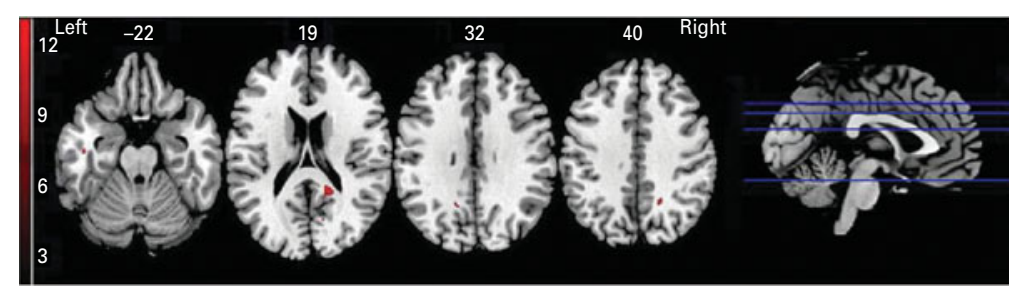

Fig. 2. Comparison among the positive family history (PFH), negative family history (NFH) and control groups: in the right cerebral sublobar extranuclear white matter (WM) of the corpus callosum (RCC), left cerebral temporal lobe subgyral WM (LT), left cerebral occipital lobe precuneus (LOP) and right cerebral parietal lobe precuneus (RPP) regions, lower fractional anisotropy (FA) values were obtained in the NFH group than in the PFH group at the voxel level $(p<0.001)$.

et al. 2008) and we note that widespread cortical thinning was documented both in the occipital region in first-episode schizophrenia (Narr et al. 2009) and in the parietal and, subsequently, temporal regions of individuals with very early onset schizophrenia (Thompson et al. 2001). Observing over a 5-year period, Thompson et al. (2001) noted that progressive tissue loss correlated with psychotic symptom severity in addition to sensorimotor (including visuospatial and auditory functions) and executive function impairments. As cortical thinning reflects smaller neuropil and neuronal size with synaptic, dendritic and axonal reorganization (Harrison, 1999), this suggests that disconnectivity worsens over time. Previous functional imaging studies have also indicated that abnormal activity in the precuneus was related to working memory performance of patients with schizophrenia (Addington et al. 2007; Schneider et al. 2007). Overall, we interpret our findings as evidence of temporo-parieto-occipital disconnectivity in first-episode patients compared with controls.

Several studies have suggested that patients with PFH may have more severe psychopathological changes (e.g. psychotic symptoms, neurocognitive functioning and abnormal brain morphology) than those in patients with NFH (Gottesman \& Gould, 2003). Additionally, Boos et al. (2007) found that brain abnormalities are present in non-psychotic first-degree relatives of patients with schizophrenia and are most pronounced in the hippocampus. Van Erp et al. (2002) found that hippocampal volumes in patients with schizophrenia spectrum disorders may be influenced in part by schizophrenia susceptibility genes and the interaction of these genes with foetal hypoxia. However, previous studies have also provided some inconsistent evidence. For example, Schulze et al. (2003) reported that hippocampal volume loss was unrelated to familial liability to schizophrenia but instead was associated with exposure to obstetric complications. Wood et al. (2005) studied a group of subjects with ultra-high risk for developing psychosis and found that ultra-high-risk subjects without a family history of schizophrenia rather than those with higher genetic loading (PFH for schizophrenia) displayed a greater degree of structural brain abnormalities in the hippocampus and anterior cingulum. To our knowledge, no study has examined the effects of family history on WM tract integrity in schizophrenia.

Based on our current findings, genetic susceptibility due to PFH of psychosis is not sufficient to alter WM tract integrity significantly in the RCC, RPP, LT and LOP WM. Other influences, such as environmental factors and obstetric complications, may play independent or combined roles in the WM abnormalities seen in schizophrenia. However, a family history of mental illness may lead to increased vigilance and awareness within the family environment, resulting in 
Table 3. Comparison of the PFH, NFH and control groups

\begin{tabular}{|c|c|c|c|c|c|c|c|c|c|}
\hline \multirow{3}{*}{$\begin{array}{l}\text { Region (MNI } \\
\text { coordinates) }\end{array}$} & \multirow[b]{3}{*}{ K } & \multirow{2}{*}{\multicolumn{2}{|c|}{$F$ test }} & \multicolumn{3}{|c|}{ Mean FA values of cluster } & \multirow{3}{*}{$\begin{array}{l}\text { PFH } v . \\
\text { Control } \\
\text { group }\end{array}$} & \multirow{3}{*}{$\begin{array}{l}\text { NFH } v \text {. } \\
\text { Control } \\
\text { group }\end{array}$} & \multirow{3}{*}{$\begin{array}{l}\text { PFH } v . \\
\text { NFH } \\
\text { group }\end{array}$} \\
\hline & & & & \multirow{2}{*}{$\begin{array}{l}\text { PFH } \\
\text { group }\end{array}$} & \multirow{2}{*}{$\begin{array}{l}\text { NFH } \\
\text { group }\end{array}$} & \multirow[b]{2}{*}{ Control } & & & \\
\hline & & $F$ & $p$ & & & & & & \\
\hline $\mathrm{LT}(-45,-15,-22)$ & 83 & 142.56 & 0.0001 & 0.441 & 0.341 & 0.523 & 0.0001 & 0.0001 & 0.0001 \\
\hline $\operatorname{RCC}(18,-46,19)$ & 238 & 159.9 & 0.0001 & 0.510 & 0.409 & 0.613 & 0.0001 & 0.0001 & 0.0001 \\
\hline $\operatorname{LOP}(-15,-57,32)$ & 63 & 98.57 & 0.0001 & 0.419 & 0.352 & 0.523 & 0.0001 & 0.0001 & 0.001 \\
\hline $\operatorname{RPP}(19,-54,40)$ & 112 & 115.9 & 0.0001 & 0.442 & 0.371 & 0.545 & 0.0001 & 0.0001 & 0.0001 \\
\hline
\end{tabular}

LT, Left cerebral temporal lobe subgyral white matter (WM); RCC, right cerebral sublobar extranuclear WM of corpus callosum; LOP, left cerebral occipital lobe precuneus; RPP, right cerebral parietal lobe precuneus; $K$, number of voxels; MNI, Montreal Neurological Institute; FA, fractional anisotropy; NFH, negative family history; $\mathrm{PFH}$, positive family history.

early detection and treatment, which may partly explain the effect of less severe anisotropy. In this study, there were no differences in age at onset and severity of symptoms between two groups of patients with or without family history, although patients with PFH may be more severely affected by genetic liability. Given that there were far fewer first-degree relatives with $\mathrm{PFH}$ than second-degree relatives, a subgroup analysis to quantify the relationship between degree of genetic liability and FA was not possible in this study.

Recent studies of copy number variations (CNVs) have provided new insights into the explanation for this finding, including an excess of rare de novo CNVs in non-familial (rather than familial) schizophrenia compared to unaffected controls and also an association with specific high-risk (genotypic odds ratio 3-11) CNVs at chromosomes 15q11.2, 15q13.3, 1q21.1, 2p, 16p13.1 and 16p11.2 ( $\mathrm{Xu}$ et al. 2008). Therefore, some of the phenotypes (e.g. brain structural abnormalities, impaired WM tract integrity) in patients with NFH may be influenced by de novo CN mutation and produce worse or independent forms than the phenotypes in patients with PHF. Of course, the hypothesis needs further testing, including exploration of the inter-relationship between WM deficits, family history and specific high-risk genetic variants such as de novo CNVs.

Some confounding factors may affect WM tract integrity, including the effects of illness chronicity, medication use, and so on. In the present study, patients with first-episode schizophrenia were recruited. By the time of entering the study, all the patients were either antipsychotic-naive or on low dosage of antipsychotics. Therefore, the potential confounding effects due to the previously mentioned factors were controlled as well as possible. Furthermore, we used voxel-based analysis, which may avoid the selective biases arising from the use of traditional region of interest (ROI) methodology.
Our study had two major limitations. First, ANCOVA of three levels found significant differences at the voxel level only. Therefore, our findings may be regarded as preliminary, and need to be clarified in independent studies. Second, as reported in previous studies (Rijsdijk et al. 2005), the structural morphological anomalies are partly affected by environment factors. Thus, the WM tract integrity in the patients with NFH could have been more severely impaired by non-genetic factors such as adverse environmental factors. However, we are unable to account for these factors because of lack of information.

In conclusion, we confirmed that WM tract integrity, especially in the temporal lobe and corpus callosum, is impaired in the early stage of schizophrenia by analysing a relatively large sample from a Han Chinese population. Our finding is the first to report that patients with NFH have more severely WM tract integrity impairment than patients with $\mathrm{PFH}$, which supports the hypothesis that different aetiological contributions pertain to non-familial and familial schizophrenia respectively.

\section{Acknowledgements}

This work was funded partly by the National Nature Science Foundation of China (grant 30971056 to W.Q. ; grants 30530300 and 30125014 to T.L.), the National Basic Research Programme of China (973 Programme 2007CB512301 to T.L.; 2007CB512305 to Q.G.), the NARSAD Independent Investigator Award (T.L.), and the Wellcome Trust (International Collaborative Award to T.L., D.A.C. and X.L.). We also thank two anonymous reviewers for their comprehensive comments, which greatly improved the manuscript.

\section{Declaration of Interest}

None. 


\section{References}

Addington AM, Gornick MC, Shaw P, Seal J, Gogtay N, Greenstein D, Clasen L, Coffey M, Gochman P, Long R, Rapoport JL (2007). Neuregulin 1 (8p12) and childhoodonset schizophrenia: susceptibility haplotypes for diagnosis and brain developmental trajectories. Molecular Psychiatry 12, 195-205.

Ardekani BA, Nierenberg J, Hoptman MJ, Javitt DC, Lim KO (2003). MRI study of white matter diffusion anisotropy in schizophrenia. Neuroreport 14, 2025-2029.

Ashburner J, Friston KJ (2005). Unified segmentation. NeuroImage 26, 839-851.

Assaf Y, Pasternak O (2008). Diffusion tensor imaging (DTI)-based white matter mapping in brain research: a review. Journal of Molecular Neuroscience 34, 51-61.

Baare WF, van Oel CJ, Hulshoff Pol HE, Schnack HG, Durston S, Sitskoorn MM, Kahn RS (2001). Volumes of brain structures in twins discordant for schizophrenia. Archives of General Psychiatry 58, 33-40.

Bartley AJ, Jones DW, Weinberger DR (1997). Genetic variability of human brain size and cortical gyral patterns. Brain 120, 257-269.

Bloom JS, Hynd GW (2005). The role of the corpus callosum in interhemispheric transfer of information: excitation or inhibition? Neuropsychology Review 15, 59-71.

Boos HB, Aleman A, Cahn W, Hulshoff Pol H, Kahn RS (2007). Brain volumes in relatives of patients with schizophrenia: a meta-analysis. Archives of General Psychiatry 64, 297-304.

Callicott JH, Weinberger DR (1999). Neuropsychiatric dynamics: the study of mental illness using functional magnetic resonance imaging. European Journal of Radiology 30, 95-104.

Cannon TD, Thompson PM, van Erp TG, Toga AW, Poutanen VP, Huttunen M, Lonnqvist J, StanderskjoldNordenstam CG, Narr KL, Khaledy M, Zoumalan CI, Dail R, Kaprio J (2002). Cortex mapping reveals regionally specific patterns of genetic and disease-specific gray-matter deficits in twins discordant for schizophrenia. Proceedings of the National Academy of Sciences USA 99, 3228-3233.

Cheung V, Cheung C, McAlonan GM, Deng Y, Wong JG, Yip L, Tai KS, Khong PL, Sham P, Chua SE (2008). A diffusion tensor imaging study of structural dysconnectivity in never-medicated, first-episode schizophrenia. Psychological Medicine 38, 877-885.

Cheung V, Chiu CPY, Law CW, Cheung C, Hui CLM, Chan KKS, Sham PC, Deng MY, Tai KS, Khong Pl, McAlonan GM, Chua SE, Chen E (2010). Positive symptoms and white matter microstructure in never-medicated first-episode schizophrenia. Psychological Medicine. Published online: 1 September 2010. doi:10.1017/S003329171000156X

DeLisi LE (2001). Speech disorder in schizophrenia: review of the literature and exploration of its relation to the uniquely human capacity for language. Schizophrenia Bulletin 27, 481-496.

DeLisi LE, Dauphinais ID, Gershon ES (1988). Perinatal complications and reduced size of brain limbic structures in familial schizophrenia. Schizophrenia Bulletin 14, 185-191.
Firbank MJ, Harrison RM, Williams ED, Coulthard A (2000). Quality assurance for MRI: practical experience. British Journal of Radiology 73, 376-383.

Friston KJ (1998). The disconnection hypothesis. Schizophrenia Research 30, 115-125.

Friston KJ, Frith CD (1995). Schizophrenia: a disconnection syndrome? Clinical Neuroscience 3, 89-97.

Gasparotti R, Valsecchi P, Carletti F, Galluzzo A, Liserre R, Cesana B, Sacchetti E (2009). Reduced fractional anisotropy of corpus callosum in first-contact, antipsychotic drug-naive patients with schizophrenia. Schizophrenia Research 108, 41-48.

Gogtay N, Sporn A, Clasen LS, Greenstein D, Giedd JN, Lenane M, Gochman PA, Zijdenbos A, Rapoport JL (2003). Structural brain MRI abnormalities in healthy siblings of patients with childhood-onset schizophrenia. American Journal of Psychiatry 160, 569-571.

Goldman AL, Pezawas L, Mattay VS, Fischl B, Verchinski BA, Zoltick B, Weinberger DR, Meyer-Lindenberg A (2008). Heritability of brain morphology related to schizophrenia: a large-scale automated magnetic resonance imaging segmentation study. Biological Psychiatry 63, 475-483.

Gottesman II, Gould TD (2003). The endophenotype concept in psychiatry: etymology and strategic intentions. American Journal of Psychiatry 160, 636-645.

Green MF, Olivier B, Crawley JN, Penn DL, Silverstein S (2005). Social cognition in schizophrenia: recommendations from the Measurement and Treatment Research to Improve Cognition in Schizophrenia New Approaches Conference. Schizophrenia Bulletin 31, 882-887.

Hall RC (1995). Global assessment of functioning. A modified scale. Psychosomatics 36, 267-275.

Harrison PJ (1999). The neuropathology of schizophrenia. A critical review of the data and their interpretation. Brain 122, 593-624.

Harrison PJ (2004). The hippocampus in schizophrenia: a review of the neuropathological evidence and its pathophysiological implications. Psychopharmacology (Berlin) 174, 151-162.

Harrison PJ, Weinberger DR (2005). Schizophrenia genes, gene expression, and neuropathology: on the matter of their convergence. Molecular Psychiatry 10, 40-68.

Ho BC (2007). MRI brain volume abnormalities in young, nonpsychotic relatives of schizophrenia probands are associated with subsequent prodromal symptoms. Schizophrenia Research 96, 1-13.

Hof PR, Haroutunian V, Friedrich Jr. VL, Byne W, Buitron C, Perl DP, Davis KL (2003). Loss and altered spatial distribution of oligodendrocytes in the superior frontal gyrus in schizophrenia. Biological Psychiatry 53, 1075-1085.

Honea RA, Meyer-Lindenberg A, Hobbs KB, Pezawas L, Mattay VS, Egan MF, Verchinski B, Passingham RE, Weinberger DR, Callicott JH (2008). Is gray matter volume an intermediate phenotype for schizophrenia? A voxel-based morphometry study of patients with schizophrenia and their healthy siblings. Biological Psychiatry 63, 465-474.

Hulshoff Pol HE, Schnack HG, Mandl RC, Brans RG, van Haren NE, Baare WF, van Oel CJ, Collins DL, 
Evans AC, Kahn RS (2006a). Gray and white matter density changes in monozygotic and same-sex dizygotic twins discordant for schizophrenia using voxel-based morphometry. NeuroImage 31, 482-488.

Hulshoff Pol HE, Schnack HG, Mandl RC, Cahn W, Collins DL, Evans AC, Kahn RS (2004). Focal white matter density changes in schizophrenia: reduced inter-hemispheric connectivity. NeuroImage 21, 27-35.

Hulshoff Pol HE, Schnack HG, Posthuma D, Mandl RC, Baare WF, van Oel C, van Haren NE, Collins DL, Evans AC, Amunts K, Burgel U, Zilles K, de Geus E, Boomsma DI, Kahn RS (2006b). Genetic contributions to human brain morphology and intelligence. Journal of Neuroscience 26, 10235-10242.

Jia Z, Huang X, Wu Q, Zhang T, Lui S, Zhang J, Amatya N, Kuang W, Chan RC, Kemp GJ, Mechelli A, Gong Q (2010). High-field magnetic resonance imaging of suicidality in patients with major depressive disorder. American Journal of Psychiatry 167, 1381-1390.

Job DE, Whalley HC, Johnstone EC, Lawrie SM (2005). Grey matter changes over time in high risk subjects developing schizophrenia. NeuroImage 25, 1023-1030.

Job DE, Whalley HC, McConnell S, Glabus M, Johnstone EC, Lawrie SM (2003). Voxel-based morphometry of grey matter densities in subjects at high risk of schizophrenia. Schizophrenia Research 64, 1-13.

Job DE, Whalley HC, McIntosh AM, Owens DG, Johnstone EC, Lawrie SM (2006). Grey matter changes can improve the prediction of schizophrenia in subjects at high risk. BMC Medicine 4, 29.

Kanaan RAA, Kim J-S, Kaufmann WE, Pearlson GD, Barker GJ, McGuire PK (2005). Diffusion tensor imaging in schizophrenia. Biological Psychiatry 58, 921-929.

Karlsgodt KH, van Erp TGM, Poldrack RA, Bearden CE, Nuechterlein KH, Cannon TD (2008). Diffusion tensor imaging of the superior longitudinal fasciculus and working memory in recent-onset schizophrenia. Biological Psychiatry 63, 512-518.

Kay SR, Fiszbein A, Opler LA (1987). The positive and negative syndrome scale (PANSS) for schizophrenia. Schizophrenia Bulletin 13, 261-276.

Ke X, Tang T, Hong S, Hang Y, Zou B, Li H, Zhou Z, Ruan Z, Lu Z, Tao G (2009). White matter impairments in autism, evidence from voxel-based morphometry and diffusion tensor imaging. Brain Research 1265, 171-177.

Kim DI, Mathalon DH, Ford JM, Mannell M, Turner JA, Brown GG, Belger A, Gollub R, Lauriello J, Wible C, O'Leary D, Lim K, Toga A, Potkin SG, Birn F, Calhoun VD (2009). Auditory oddball deficits in schizophrenia: an independent component analysis of the fMRI multisite function BIRN study. Schizophrenia Bulletin 35, 67-81.

Koolschijn PC, van Haren NE, Hulshoff Pol HE, Kahn RS (2008). Hypothalamus volume in twin pairs discordant for schizophrenia. European Neuropsychopharmacology 18, 312-315.

Kubicki M, McCarley R, Westin C-F, Park H-J, Maier S, Kikinis R, Jolesz FA, Shenton ME (2007). A review of diffusion tensor imaging studies in schizophrenia. Journal of Psychiatric Research 41, 15-30.
Kubicki M, Shenton ME, Salisbury DF, Hirayasu Y, Kasai K, Kikinis R, Jolesz FA, McCarley RW (2002a). Voxel-based morphometric analysis of gray matter in first episode schizophrenia. NeuroImage 17, 1711-1719.

Kubicki M, Westin CF, Maier SE, Frumin M, Nestor PG, Salisbury DF, Kikinis R, Jolesz FA, McCarley RW, Shenton ME (2002b). Uncinate fasciculus findings in schizophrenia: a magnetic resonance diffusion tensor imaging study. American Journal of Psychiatry 159, 813-820.

Kubicki M, Westin CF, McCarley RW, Shenton ME (2005). The application of DTI to investigate white matter abnormalities in schizophrenia. Annals of the New York Academy of Sciences 1064, 134-148.

Kubicki M, Westin CF, Nestor PG, Wible CG, Frumin M, Maier SE, Kikinis R, Jolesz FA, McCarley RW, Shenton ME (2003). Cingulate fasciculus integrity disruption in schizophrenia: a magnetic resonance diffusion tensor imaging study. Biological Psychiatry 54, 1171-1180.

Lawrie SM, Buechel C, Whalley HC, Frith CD, Friston KJ, Johnstone EC (2002). Reduced frontotemporal functional connectivity in schizophrenia associated with auditory hallucinations. Biological Psychiatry 51, 1008-1011.

Lee K, Yoshida T, Kubicki M, Bouix S, Westin CF, Kindlmann G, Niznikiewicz M, Cohen A, McCarley RW, Shenton ME (2009). Increased diffusivity in superior temporal gyrus in patients with schizophrenia: a diffusion tensor imaging study. Schizophrenia Research 108, 33-40.

Lim KO, Hedehus M, Moseley M, de Crespigny A, Sullivan EV, Pfefferbaum A (1999). Compromised white matter tract integrity in schizophrenia inferred from diffusion tensor imaging. Archives of General Psychiatry 56, 367-374.

Liu Y, Liang M, Zhou Y, He Y, Hao Y, Song M, Yu C, Liu H, Liu Z, Jiang T (2008). Disrupted small-world networks in schizophrenia. Brain 131, 945-961.

McDonald C, Marshall N, Sham PC, Bullmore ET, Schulze K, Chapple B, Bramon E, Filbey F, Quraishi S, Walshe M, Murray RM (2006). Regional brain morphometry in patients with schizophrenia or bipolar disorder and their unaffected relatives. American Journal of Psychiatry 163, 478-487.

Minami T, Nobuhara K, Okugawa G, Takase K, Yoshida T, Sawada S, Ha-Kawa S, Ikeda K, Kinoshita T (2003).

Diffusion tensor magnetic resonance imaging of disruption of regional white matter in schizophrenia.

Neuropsychobiology 47, 141-145.

Narr KL, Hageman N, Woods RP, Hamilton LS, Clark K, Phillips O, Shattuck DW, Asarnow RF, Toga AW, Nuechterlein KH (2009). Mean diffusivity: a biomarker for CSF-related disease and genetic liability effects in schizophrenia. Psychiatry Research 171, 20-32.

Narr KL, Thompson PM, Szeszko P, Robinson D, Jang S, Woods RP, Kim S, Hayashi KM, Asunction D, Toga AW, Bilder RM (2004). Regional specificity of hippocampal volume reductions in first-episode schizophrenia. NeuroImage 21, 1563-1575.

Phillips OR, Nuechterlein KH, Clark KA, Hamilton LS, Asarnow RF, Hageman NS, Toga AW, Narr KL (2009) Fiber tractography reveals disruption of temporal lobe white matter tracts in schizophrenia. Schizophrenia Research $107,30-38$. 
Price G, Bagary MS, Cercignani M, Altmann DR, Ron MA

(2005). The corpus callosum in first episode schizophrenia: a diffusion tensor imaging study. Journal of Neurology,

Neurosurgery, and Psychiatry 76, 585-587.

Rabinowicz EF, Silipo G, Goldman R, Javitt DC (2000). Auditory sensory dysfunction in schizophrenia: imprecision or distractibility? Archives of General Psychiatry 57, 1149-1155.

Ridgway GR, Omar R, Ourselin S, Hill DL, Warren JD, Fox NC (2009). Issues with threshold masking in voxel-based morphometry of atrophied brains. Neuroimage 44, 99-111.

Rijsdijk FV, van Haren NE, Picchioni MM, McDonald C, Toulopoulou T, Hulshoff Pol HE, Kahn RS, Murray R, Sham PC (2005). Brain MRI abnormalities in schizophrenia: same genes or same environment? Psychological Medicine 35, 1399-1409.

Rotarska-Jagiela A, Schonmeyer R, Oertel V, Haenschel C, Vogeley K, Linden DE (2008). The corpus callosum in schizophrenia - volume and connectivity changes affect specific regions. NeuroImage 39, 1522-1532.

Schneider F, Habel U, Reske M, Kellermann T, Stocker T, Shah NJ, Zilles K, Braus DF, Schmitt A, Schlosser R, Wagner M, Frommann I, Kircher T, Rapp A, Meisenzahl E, Ufer S, Ruhrmann S, Thienel R, Sauer H, Henn FA, Gaebel W (2007). Neural correlates of working memory dysfunction in first-episode schizophrenia patients : an fMRI multi-center study. Schizophrenia Research 89, 198-210.

Schulze K, McDonald C, Frangou S, Sham P, Grech A, Toulopoulou T, Walshe M, Sharma T, Sigmundsson T, Taylor M, Murray RM (2003). Hippocampal volume in familial and nonfamilial schizophrenic probands and their unaffected relatives. Biological Psychiatry 53, 562-570.

Shenton ME, Dickey CC, Frumin M, McCarley RW (2001). A review of MRI findings in schizophrenia. Schizophrenia Research 49, 1-52.

Steel RM, Bastin ME, McConnell S, Marshall I, Cunningham-Owens DG, Lawrie SM, Johnstone EC, Best JJ (2001). Diffusion tensor imaging (DTI) and proton magnetic resonance spectroscopy (1H MRS) in schizophrenic subjects and normal controls. Psychiatry Research 106, 161-170.
Sun Z, Wang F, Cui L, Breeze J, Du X, Wang X, Cong Z, Zhang H, Li B, Hong N, Zhang D (2003). Abnormal anterior cingulum in patients with schizophrenia: a diffusion tensor imaging study. Neuroreport 14, 1833-1836.

Thompson PM, Vidal C, Giedd JN, Gochman P, Blumenthal J, Nicolson R, Toga AW, Rapoport JL (2001). Mapping adolescent brain change reveals dynamic wave of accelerated gray matter loss in very early-onset schizophrenia. Proceedings of the National Academy of Sciences USA 98, 11650-11655.

Van Erp TG, Saleh PA, Rosso IM, Huttunen M, Lonnqvist J, Pirkola T, Salonen O, Valanne L, Poutanen VP, Standertskjold-Nordenstam CG, Cannon TD (2002). Contributions of genetic risk and fetal hypoxia to hippocampal volume in patients with schizophrenia or schizoaffective disorder, their unaffected siblings, and healthy unrelated volunteers. American Journal of Psychiatry 159, 1514-1520.

Wang F, Sun Z, Cui L, Du X, Wang X, Zhang H, Cong Z, Hong N, Zhang D (2004). Anterior cingulum abnormalities in male patients with schizophrenia determined through diffusion tensor imaging. American Journal of Psychiatry 161, 573-575.

Wang F, Sun Z, Du X, Wang X, Cong Z, Zhang H, Zhang D, Hong $N$ (2003). A diffusion tensor imaging study of middle and superior cerebellar peduncle in male patients with schizophrenia. Neuroscience Letters 348, 135-138.

Winterer G, Konrad A, Vucurevic G, Musso F, Stoeter P, Dahmen N (2008). Association of 5' end neuregulin-1 (NRG1) gene variation with subcortical medial frontal microstructure in humans. NeuroImage 40, 712-718.

Wood SJ, Yucel M, Velakoulis D, Phillips LJ, Yung AR, Brewer W, McGorry PD, Pantelis C (2005). Hippocampal and anterior cingulate morphology in subjects at ultra-high-risk for psychosis: the role of family history of psychotic illness. Schizophrenia Research 75, 295-301.

Xu B, Roos JL, Levy S, van Rensburg EJ, Gogos JA, Karayiorgou M (2008). Strong association of de novo copy number mutations with sporadic schizophrenia. Nature Genetics 40, 880-885.

Yamada M, Hirao K, Namiki C, Hanakawa T, Fukuyama H, Hayashi T, Murai T (2007). Social cognition and frontal lobe pathology in schizophrenia: a voxel-based morphometric study. NeuroImage 35, 292-298. 